\title{
Inovação e orientação para o mercado e desempenho no arranjo produtivo local embrionário do vestuário de Londrina/PR
}

\author{
Fabiano Palhares Galão ${ }^{1}$ \\ Marcia Regina Gabardo Da Camara ${ }^{2}$
}

\section{Resumo}

A pesquisa analisa o impacto da inovação e da orientação para o mercado sobre o desempenho das empresas do arranjo produtivo local do vestuário de Londrina. Identifica o grau de orientação para o mercado através da escala Markor, segundo Kohli, Jaworski e Kumar (1993), e a implementação de inovações de produto, processos e inovações organizacionais. O método escolhido é o survey, envolvendo uma amostra de 62 empresas, e foram utilizados o coeficiente de correlação de Pearson e a análise de Clusters. Conclui-se que: a) as empresas são altamente orientadas para o mercado; b) o comportamento inovador do arranjo é baixo; c) o lançamento de novos produtos é a prática inovadora mais utilizada pelas empresas; e d) a orientação para o mercado e a inovação contribuem para o crescimento do faturamento e para o retorno do investimento das indústrias do vestuário de Londrina.

Palavras-chave: Orientação para o mercado. Inovação. Competitividade. Indústria do vestuário.

\section{Introdução}

As grandes mudanças, as incertezas ambientais, a complexidade e intensidade competitiva têm levado as empresas a uma avaliação das práticas de negócios. Nesse sentido, a competitividade e o sucesso delas dependem da capacidade inovativa, identificada como fator crítico de sucesso. $\mathrm{Na}$ indústria do vestuário, a implementação de inovações tem sido decisiva, a par-

\footnotetext{
${ }^{1}$ Doutorando em Administração pela FEA-USP e Mestre em Administração pelo PPA- UEM/UEL. Docente da UNOPAR(Universidade Norte do Paraná). Endereço: Av. Voluntários da Pátria, 546 - apto 702 -CEP 86061-120 -Londrina-PR. E-mail: fabiano.galao@unopar.br.

${ }^{2}$ Doutora em Teoria Econômica FIPE-USP. Docente do Programa de Mestrado em Economia Regional (PPE- Universidade Estadual de Londrina) e do Programa de Mestrado em Administração (PPA-UEM/UEL). Endereço: Rua Belo Horizonte, 734 ap.16 - CEP $86020-060$ - Londrina PR. Email:mgabardo@uel.br. Artigo recebido em: 27/01/2007. Aceito em: 21/05/2008. Membro do Corpo Editorial Científico responsável pelo processo editorial: Gilberto de Oliveira Moritz.
} 
tir do início dos anos 90, dada a abertura do mercado à concorrência internacional e à estabilização da moeda brasileira.

Lastres e Cassiolato (2003) afirmam que os formatos organizacionais que privilegiam a interação e a atuação conjunta dos mais variados agentes, como redes, arranjos e sistemas produtivos, vêm se consolidando como os mais adequados para promover a geração, aquisição e difusão de conhecimento e inovações. $\mathrm{O}$ artigo também destaca a importância da orientação para o mercado como sendo um dos fatores de competitividade para o setor. Dessa forma, este estudo analisa o impacto da inovação e da orientação para o mercado sobre o desempenho das empresas do arranjo produtivo local de Londrina, apresenta o referencial teórico, a metodologia da pesquisa, apresenta os resultados e por fim, as conclusões e recomendações.

\section{Arranjos Produtivos Locais}

O interesse pelo estudo de aglomerações geográficas de empresas tem origem nas mudanças ocorridas a partir da década de 70, no ambiente competitivo das organizações. Para Santos, Crocco e Simões (2003) tais mudanças ocorrem simultaneamente com a emergência de um novo paradigma tecnológico, que impõe um processo produtivo mais intensivo em conhecimento, e pela liberalização econômica, que derrubou as tradicionais barreiras de comércio, alterando significativamente o ambiente competitivo e colocando grandes dificuldades para as pequenas e médias empresas.

Santos, Crocco e Lemos (2003) afirmam que existe um relativo consenso entre os vários estudos sobre as micro, pequenas e médias empresas: a solução para os desafios enfrentados por elas passaria pela formação de redes cooperativas. Os estudos sobre vantagens de arranjos produtivos locais para o desenvolvimento tecnológico e regional de um país apontam que empresas aglomeradas territorialmente podem se beneficiar da aglomeração através das chamadas economias externas. Para Suzigan et al. (2003) as economias externas, incidental ou deliberadamente criadas, contribuem para o incremento da competitividade das empresas e, em consequência, do sistema ou arranjo local como um todo. As economias externas podem ser incidentais, decorrentes da (i) existência de um vasto contingente de mãode-obra especializada e com habilidades específicas ao sistema local; (ii) pre- 
sença e atração de um conjunto de fornecedores especializados de matériaprima, componentes e serviços, e (iii) grande disseminação dos conhecimentos, habilidades e informações concernentes ao ramo de atividade dos produtores locais.

As economias externas de caráter incidental foram apontadas por Marshall, em Principles of Economics, de 1890, em seu pioneiro trabalho sobre os distritos industriais ingleses. Marshall (1982) ressaltou os benefícios que a localização em certos lugares representava para determinadas indústrias, numa abordagem em que as economias externas configuravam o principal foco de vantagens para cada produtor individual. Para Lastres et al. (1998) a abordagem de Marshall sobre os distritos industriais fundamentou os recentes trabalhos sobre o tema, tornando-se referência de arranjos locais de desenvolvimento industrial.

Suzigan et al. (2003) complementam que, além das economias externas incidentais, os agentes locais (empresas e instituições) podem reforçar sua capacidade competitiva por meio de ações conjuntas deliberadas - compra de matérias-primas, promoção de cursos de capacitação gerencial e formação profissional, criação de consórcios de exportação, contratação de serviços especializados, estabelecimento de centros tecnológicos de uso coletivo, cooperativas de crédito, entre outros. De acordo com Lastres e Cassiolato (2003), a aglomeração de empresas e o aproveitamento das sinergias coletivas geradas pelas interações vêm efetivamente fortalecendo as chances de sobrevivência e crescimento, constituindo-se em importante fonte geradora de vantagens competitivas. Garcia, Motta e Amato Neto (2004, p. 343) afirmam que

[...] a literatura que aborda aglomerações tem mostrado que as empresas pertencentes a estes sistemas, tanto de países desenvolvidos como em países em desenvolvimento, são capazes de obter vantagens competitivas em relação às empresas dispersas geograficamente.

Para Telles (2002) a eficiência coletiva é a vantagem competitiva que vem das externalidades e da ação conjunta, e essa ação promove grande diferencial de competitividade entre as empresas aglomeradas e empresas que estão dispersas territorialmente. 


\section{Tipologias e Caracterizações de Arranjos Produtivos Locais}

A RedeSist (Rede de Sistemas Produtivos e Inovativos Locais) desenvolveu os conceitos de arranjos produtivos locais (APLs) e sistemas produtivos e inovativos locais (SPILs). Para Cassiolato e Lastres (2004) a ênfase em sistemas e arranjos produtivos locais privilegia a investigação das relações entre conjuntos de empresas e destas com outros atores; dos fluxos de conhecimento, em particular, em sua dimensão tácita; das bases dos processos de aprendizado para as capacitações produtivas, organizacionais e inovadoras; da importância da proximidade geográfica e identidade histórica, institucional, social e cultural como fontes de diversidade e vantagens competitivas. De acordo com os referidos autores:

Sistemas Produtivos e Inovativos Locais - SPILs - desig-
na conjuntos de agentes econômicos, políticos e sociais,
localizados em um mesmo território, desenvolvendo ativi-
dades econômicas correlatas e que apresentam vínculos
expressivos de interação, cooperação e aprendizagem.
SPILs geralmente incluem empresas - produtoras de bens
e serviços finais, fornecedoras de insumos e equipamen-
tos, prestadoras de serviços, comercializadoras, clientes,
etc., cooperativas, associações e representações - e de-
mais organizações voltadas à formação e treinamento de
recursos humanos, informação, pesquisa, desenvolvimen-
to e engenharia, promoção e financiamento. Já o termo
Arranjos Produtivos Locais designa aqueles casos de sis-
temas fragmentados e que não apresentam significativa
articulação entre os agentes (CASSIOLATO; LASTRES,
2004, p. 6).

As aglomerações industriais são caracterizadas por fatores relacionados à dimensão territorial, à diversidade de atividades e atores econômicos, políticos e sociais, ao conhecimento tácito, aos processos de inovação e aprendizado interativo, às formas de governança, e ao grau de enraizamento (LASTRES; CASSIOLATO, 2004). O enfoque do presente artigo será dado aos conceitos de inovação.

Para Lastres e Cassiolato (2004) as abordagens sobre o caráter e o papel da inovação foram desenvolvidas particularmente pela corrente 
evolucionária do pensamento econômico, calcada nos trabalhos de Richard Nelson, Sidney Winter, Christopher Freeman, Giovanni Dosi, Carlota Perez, dentre outros, e fundamentados em Schumpeter. Tal corrente parte dos seguintes pressupostos centrais: (i) o conhecimento é a base do processo inovador, e sua criação, uso e difusão alimentam a mudança econômica, constituindo-se em importante fonte de competitividade; (ii) o aprendizado é o mecanismo chave no processo de acumulação de conhecimentos; (iii) a empresa é considerada o ponto mais importante nesse processo; porém o processo de inovação é geralmente interativo, contando com a contribuição de vários agentes, detentores de diferentes tipos de informações e conhecimentos, dentro e fora da empresa; (iv) os processos de aprendizado, capacitação e inovação são influenciados e influenciam os ambientes sócio-econômicopolíticos onde se realizam.

O presente trabalho adota como conceito de inovação o proposto por Dosi (1988). Segundo o autor, a inovação caracteriza-se pela busca, descoberta, experimentação, desenvolvimento, imitação e adoção de novos produtos, processos e novas técnicas organizacionais.

Segundo Lastres e Cassiolato (2004) até a década de 60, a inovação era vista como um processo linear, ocorrendo em estágios sucessivos e independentes que se iniciava com as atividades de pesquisa básica e terminava na adoção de novos produtos e processos pela empresa. Porém, Lemos (2001) salienta que, longe de ser linear, o processo inovador se caracteriza por ser descontínuo, irregular e possui um considerável grau de incerteza, posto que a solução dos problemas existentes e as consequências das resoluções são desconhecidas a priori. Dosi (1988) afirma que os diferentes aspectos da inovação a tornam um processo complexo, interativo e não linear. Quando combinados aos conhecimentos adquiridos e aos avanços na pesquisa científica, e adicionadas as necessidades oriundas do mercado, as inovações em produtos e processos conduzem a mudanças na base tecnológica e organizacional de uma empresa. Essa noção da inovação como processo é destacada por Lastres e Cassiolato (2004) que atestam que isso ocorreu a partir da década de 70, quando se ampliou o entendimento da inovação, que passou a ser vista não mais como um ato isolado, mas como um processo, de múltiplas fontes, derivando de complexas interações entre agentes.

Para Sousa e Cavalcanti Filho (2004) o processo inovador é o fator dinâmico do crescimento, e para isso depende dos processos interativos de natureza social, na qual o aprendizado (que pode ser obtido individualmente ou de maneira coletiva, ou ainda proporcionado por instituições e organi- 
zações) é a fonte principal da mudança. Esse processo depende da existência de diversidade de estratégias de ação das empresas e de diferentes interações tecnológicas entre os agentes, resultantes da troca de conhecimentos nos processos de aprendizado, possibilitados pelas características locais, culturais e sociais comuns.

O caráter localizado da inovação e do conhecimento ganhou destaque a partir do início da década de 80. A propósito, Lastres e Cassiolato (2004) esclarecem que, nessa época, se desfaz o entendimento de que a inovação deve ser algo absolutamente novo, em termos mundiais, passando a ser percebida como o processo que as empresas dominam e implementam o desenvolvimento e a produção de bens e serviços, que sejam novos para elas, independentemente do fato de serem novos para seus concorrentes - domésticos ou internacionais.

\section{A Inovação do Setor Têxtil-Vestuário}

A classificação sugerida por Pavitt (1984) auxilia na compreensão da dinâmica inovadoras da indústria têxtil-vestuário. Pavitt (1984) classificou os setores industriais conforme seus padrões inovadores e tecnológico. Inicialmente o referido autor definiu quatro categorias de empresas: supplier dominated (dominados pelos fornecedores); scale intensive (intensivos em escala); specialized suppliers (fornecedores especializados) e science based (baseados em ciência).

O setor de vestuário, foco deste trabalho, em relação à sua trajetória tecnológica, é classificado por Pavitt (1984) como dominado por fornecedores, pois nesse grupo predominam as pequenas empresas e as escolhas tecnológicas estão, normalmente, baseadas em redução de custos, sendo que as oportunidades para o acúmulo de conhecimento tecnológico são relativamente baixas. O foco é direcionado para a otimização e modificações nos métodos produtivos e na diversificação e melhoria do produto final e as empresas podem utilizar de práticas de marketing e desenvolvimento de marcas como barreiras à imitação. A maior parte das atividades inovadoras efetivadas no setor é direcionada a inovações de processo, entretanto essas indústrias respondem pela realização de apenas uma pequena parte dessas inovações: a maioria é proveniente de fornecedores de máquinas, equipamentos e componentes de produção. 
Utilizando a taxonomia de Pavitt (1984), Campos, Cário e Nicolau (2000) afirmam que a indústria têxtil-vestuário é dominada pelos fornecedores da indústria de bens de capital - que desenvolvem e aprimoram suas máquinas e equipamento - e da indústria química, cuja vinculação com setores baseados em ciência possibilita melhorias nas performances de fibras, corantes, fixadores, tintas, etc., repercutindo na dinâmica industrial setorial têxtil-vestuário.

Uma vez que as características inovadoras do setor do vestuário não permitem inovações radicais, o foco será no aprimoramento contínuo do design e qualidade de produtos, e nas mudanças organizacionais, gerenciais, rotinas de marketing, entre outras, que são as inovações incrementais já discutidas anteriormente. Confirmando essa situação, FINEP (2004) observa que na indústria do vestuário as maiores inovações nos últimos anos se deram no design do produto e na organização da produção e marketing. Diante dessas características, para que esse processo de inovação baseado em melhorias de processo e produto seja efetivo, as indústrias do vestuário devem se concentrar no mercado consumidor, identificando suas necessidades e preferências, respondendo a elas de forma rápida com produtos adequados às constantes mudanças e exigências dos consumidores.

Essa aproximação com os clientes como forma de geração de inovações pode ser observado no estudo feito por Campos, Cário e Nicolau (2000). Os resultados da pesquisa apontaram que, quanto às fontes de informação para a inovação e às formas de introdução de inovações, as empresas pesquisadas, independente do tamanho, consideram as relações com os clientes como sendo a principal fonte de informações para a inovação.

A ênfase nas características do setor apresentadas por Pavitt (1984) ao mesmo tempo em que destacam o foco no mercado, segundo Kohli e Jaworski (1990), sinalizam que as indústrias que estão relativamente mal posicionadas para influenciar a tecnologia avançada, devem depender da orientação para o mercado para obter sucesso. Os resultados do estudo de Campos, Cário e Nicolau (2000) também reforçam essa condição, ao apontar que diante da dinâmica do processo inovador na indústria têxtil-vestuário, os esforços das empresas em estudo têm duas dimensões. A primeira é o esforço para acompanhar as mudanças na moda e na preferência dos consumidores e, ao mesmo tempo, os avanços tecnológicos nos fornecedores de equipamentos $e$ insumos. A segunda é o esforço interno às empresas para a capacitação tecnológica que proporcione a absorção das inovações de fontes externas. 
Hurley e Hult (1998) também destacam a relação entre inovação e foco no mercado, ao que propõem que a orientação para o mercado deveria focar na inovação como principal elemento para responder às necessidades dos mercados.

Para Kohli e Jaworski (1990) a orientação para o mercado compreende: (i) um ou mais departamentos engajados em atividades capazes de desenvolver uma compreensão das necessidades atuais e futuras dos consumidores, bem como dos fatores que os afetam, (ii) compartilhar esse entendimento entre os departamentos e (iii) os vários departamentos empenhandose em atividades planejadas a fim de ir ao encontro às necessidades do cliente. Em outras palavras, a orientação para o mercado se refere à geração de inteligência de mercado, disseminação de inteligência gerada e a capacidade de resposta da empresa à inteligência gerada. A premissa básica da orientação para o mercado é que as empresas que adotam essa postura apresentam desempenho superior. Por fim, Hooley, Saunders e Piercy (2001) afirmam que uma das condições necessárias para uma empresa inovar com sucesso é a proximidade com os consumidores, buscando entender suas necessidades e exigências

\section{Metodologia}

O método escolhido é o survey, envolvendo uma amostra de 62 empresas do APL do vestuário de Londrina. O objetivo é verificar o impacto da orientação para o mercado e da inovação no desempenho das empresas selecionadas.

As variáveis selecionadas para verificar a existência de esforços inovadores e identificar as inovações de processo, produto e gestão das indústrias do vestuário de Londrina foram: inovação de produto, inovação de processo, inovações organizacionais e atividades inovadoras. A mensuração dos indicadores de inovação foi realizada por meio de uma escala ordinal de quatro pontos, variando de baixa a alta, referente à introdução de inovações, e de baixo a alto, referente ao desenvolvimento do tipo de atividade. À escala foi adicionada a opção não existência da atividade. Utilizou-se o modelo de questionário de Cassiolato e Lastres (2004). 
Para verificar o grau de orientação para o mercado das empresas da amostra foi utilizada a escala Markor, desenvolvida por Kohli, Jaworski e Kumar (1993). A escala possui um total de 20 indicadores assim distribuídos: seis relativos à geração de inteligência de mercado (indicadores 1 a 6), cinco relativos à disseminação de inteligência de mercado (indicadores 7 a 11) e nove relativos à resposta da empresa (indicadores 12 a 20). Foram utilizadas, a exemplo da medida original, escalas de cinco pontos, tipo Likert, as quais o respondente deveria manifestar-se de acordo com o comportamento de sua empresa, variando os extremos de (1) Discordo Totalmente, a (5) Concordo Totalmente.

Os indicadores selecionados para verificar o desempenho das empresas foram: crescimento do faturamento, lucro líquido e retorno do investimento. A abordagem adotada para a verificação da performance das empresas foi feita através da perspectiva subjetiva, que está relacionada à performance das organizações segundo as suas próprias expectativas ou relativamente à competição (MENNA, 2001). Para Carneiro et al. (2005) medidas subjetivas capturam a opinião pessoal ou a percepção do respondente sobre uma determinada faceta do desempenho; tais medidas revelam-se especialmente importantes na ausência de medidas objetivas, o que tende a ser o caso em empresas pequenas ou de capital fechado. A mensuração foi realizada através de uma escala de quatro pontos, variando de um (desempenho péssimo) a quatro (desempenho excelente). Foi solicitado ao entrevistado que o mesmo indicasse o desempenho de sua indústria nos últimos dois anos em relação aos seus principais concorrentes.

Para verificar a associação entre a inovação e a orientação para o mercado no desempenho da amostra foi utilizada a análise de correlação. Para Richardson (1989, p. 30) o tipo de estudo que procura investigar a correlação entre variáveis "deve ser realizado quando o pesquisador deseja obter melhor entendimento do comportamento de diversos fatores e elementos que influem sobre determinado fenômeno". O coeficiente de correlação de Pearson foi utilizado porque fornece uma medida precisa da força e do sentido da correlação existente entre as variáveis na amostra estudada (LEVIN, 1987).

Com o objetivo de identificar grupos de empresas com características semelhantes em relação à inovação, orientação para o mercado e desempenho, os dados colhidos referentes a esses constructos foram submetidos à 
Fabiano Palhares Galão - Marcia Regina Gabardo Da Camara

Análise de Cluster. Para Mingoti (2005, p. 155), a análise de cluster ou conglomerados

[...] tem como objetivo dividir os elementos da amostra, em grupos, de forma que os elementos pertencentes a um mesmo grupo sejam similares entre si com respeito às variáveis (características) que neles foram medidas, e os elementos em grupos diferentes sejam heterogêneos em relação a estas mesmas características.

O procedimento utilizado para agrupar os casos (empresas) semelhantes foi o conglomerado hierárquico com base no método de Ward, através da medida de distância entre os casos Euclidiana ao Quadrado (HAIR Jr. et al., 2005), dando origem a três clusters conforme a média de cada constructo. Com o objetivo de verificar se as diferenças entre as médias dos clusters são estatisticamente significativas, utilizou-se a análise de variância (ANOVA). A última etapa da análise de clusters caracterizou os grupos segundo ano de fundação, porte, tipo de gestão e utilização de marca própria.

\section{Análise dos Resultados}

Arbex (2005) caracterizou o APL embrionário têxtil-vestuário de Londrina e identificou suas características, e os elos verticais, horizontais e multilaterais entre as firmas e outros agentes. A aglomeração é composta principalmente por micro e pequenas empresas, com grau incipiente de cooperação entre si, presença de governança em rede e algumas relações de subcontratação. Esse estudo verifica a existência de uma infraestrutura desenvolvida e a presença de instituições de apoio às empresas, mas os fracos elos entre os agentes e a ausência de identidade cultural entre os empresários, não facilitava as relações de cooperação. $\mathrm{O}$ autor destaca o elevado potencial para o desenvolvimento de um arranjo produtivo desenvolvido (podendo, inclusive, se tornar um sistema inovador), embora atualmente configure-se um arranjo produtivo embrionário.

A Tabela 1 apresenta as médias encontradas em relação à orientação para o mercado das empresas pesquisadas e é possível verificar que as microempresas alcançaram a maior média de orientação para o mercado de 
4,15; em seguida aparecem as pequenas empresas com média geral de orientação para o mercado de 3,92; e, por fim, as médias e grandes empresas com média de 3,45 . Esse resultado pode sugerir que o porte da empresa pode se constituir em uma barreira de orientação para o mercado.

Tabela 1: Médias de Geração de Inteligência de Mercado, Disseminação de Inteligência de Mercado, Resposta à Inteligência de Mercado e Média Geral de Orientação para o Mercado por porte das empresas.

\begin{tabular}{|l|c|c|c|c|}
\hline \multicolumn{1}{|c|}{ Constructo } & Micro & Pequena & $\begin{array}{c}\text { Média/ } \\
\text { Grande }\end{array}$ & Geral \\
\hline $\begin{array}{l}\text { Geração de Inteligência de } \\
\text { Mercado. }\end{array}$ & 3,87 & 3,56 & 3,66 & 3,77 \\
\hline $\begin{array}{l}\text { Disseminação de Inteligên- } \\
\text { cia de Mercado. }\end{array}$ & 4,10 & 3,92 & 3,04 & 3,97 \\
\hline $\begin{array}{l}\text { Resposta à Inteligência de } \\
\text { Mercado. }\end{array}$ & 4,15 & 4,16 & 3,53 & 4,23 \\
\hline $\begin{array}{l}\text { Média Geral de Orienta- } \\
\text { ção para o Mercado. }\end{array}$ & $\mathbf{4 , 1 5}$ & $\mathbf{3 , 9 2}$ & $\mathbf{3 , 4 5}$ & $\mathbf{4 , 0 2}$ \\
\hline
\end{tabular}

Fonte: Dados da pesquisa.

Nota: Os valores de cada constructo foram obtidos através da média das respostas, utilizando uma escala Likert de cinco pontos.

Na sequência são apresentados os resultados dos 17 indicadores que compõem o constructo inovação, sendo a análise realizada segmentando as empresas da amostra de acordo com o porte.

A Tabela 2 permite verificar que a introdução de produto novo para o mercado internacional (indicador 3) apresentou a menor média dos nove indicadores $(1,05)$, apontando a escassa participação das empresas da amostra no mercado internacional; o resultado reflete a realidade brasileira no que diz respeito à irrelevante participação de empresas nacionais como exportadoras de têxteis e confeccionados (IEMI, 2005). Essa característica do setor também foi apontada por Braga (2005), quando afirmou que grande parte das empresas brasileiras de vestuário tem sua produção voltada para atender ao mercado interno. 
A pesquisa revela que a introdução de produtos novos para as empresas, mas já existentes no mercado (indicador 1), tem sido prática constante por parte das indústrias da amostra, pois o indicador relacionado a esse item apresentou a maior média de todos os indicadores, 3,05. Nesse sentido, Martins (2003) coloca que o ponto principal no comportamento das empresas competitivas encontra-se nas estratégias centradas na inovação, seja pela conquista de novos mercados ou pelo lançamento de novos produtos.

Esse indicador para as médias e grandes indústrias ficou acima da média, reforçando ainda mais a prática de lançamento de novos produtos por parte dessas empresas. Articulando a média geral de orientação para o mercado das empresas da amostra, com o resultado encontrado no que diz respeito ao lançamento de produtos, Perin e Sampaio (2006) afirmam que uma forte orientação para o mercado pode afetar diretamente o desenvolvimento de novos produtos por meio de um ajuste fino entre os desejos dos clientes e os benefícios oferecidos pelo produto.

Os indicadores 4 (introdução de processos tecnológicos novos para a empresa, mas já existente no setor), 5 (introdução de processos tecnológicos novos para o setor de atuação) , 6 (implementação de técnicas avançadas de gestão) e 9 (implementação de novos métodos e gerenciamento) evidenciam a baixa capacidade de inovação das empresas do setor de vestuário, como apontado por Pavitt (1984). Segundo o referido autor, as indústrias desse setor são caracterizadas como dominadas pelos fornecedores e a maioria das inovações é proveniente de fornecedores de máquinas, equipamentos e componentes de produção.

Tabela 2: Inovação de produto, processo e gestão organizacional por porte das empresas.

\begin{tabular}{|l|c|c|c|c|}
\hline \multicolumn{1}{|c|}{ Descrição } & Micro & Pequena & $\begin{array}{c}\text { Média/ } \\
\text { Grande }\end{array}$ & Geral \\
\hline $\begin{array}{l}\text { 1. Introdução de produtos novos para a } \\
\text { empresa, mas existente no mercado. }\end{array}$ & 2,98 & 3,12 & 3,40 & 3,05 \\
\hline $\begin{array}{l}\text { 2. Introdução de produtos novos para o } \\
\text { mercado nacional. }\end{array}$ & 1,93 & 2,29 & 2,40 & 2,06 \\
\hline $\begin{array}{l}\text { 3. Introdução de produto novo para o } \\
\text { mercado internacional. }\end{array}$ & 1,05 & 1,06 & 1,00 & 1,05 \\
\hline
\end{tabular}

Fonte: Dados da pesquisa.

Nota: Os valores de cada item foram obtidos através da média das respostas. Para avaliar o grau de inovação utilizou-se a seguinte escala: 1 - não houve a atividade inovação; 2 - a taxa da inovação foi baixa; 3 - a taxa da inovação foi média; e 4 - a taxa da inovação foi alta. 
Inovação e orientação para o mercado e desempenho no arranjo produtivo local embrionário do vestuário de Londrina-PR

Tabela 2: Inovação de produto, processo e gestão organizacional por porte das empresas.

\begin{tabular}{|l|c|c|c|c|}
\hline \multicolumn{1}{|c|}{ Descrição } & Micro & Pequena & $\begin{array}{c}\text { Média/ } \\
\text { Grande }\end{array}$ & Geral \\
\hline $\begin{array}{l}\text { 4. Introdução de processos tecnológicos } \\
\text { novos para a empresa, mas já existente no } \\
\text { setor. }\end{array}$ & 2,08 & 2,24 & 2,20 & 2,13 \\
\hline $\begin{array}{l}\text { 5. Introdução de processos tecnológicos } \\
\text { novos para o setor de atuação. }\end{array}$ & 1,83 & 1,76 & 1,80 & 1,81 \\
\hline $\begin{array}{l}\text { 6. Implementação de técnicas avançadas } \\
\text { de gestão. }\end{array}$ & 2,16 & 2,00 & 2,60 & 2,13 \\
\hline $\begin{array}{l}\text { 7. Implementação de significativas mu- } \\
\text { danças na estrutura organizacional. }\end{array}$ & 2,58 & 2,65 & 2,00 & 2,55 \\
\hline $\begin{array}{l}\text { 8. Implementação de mudanças significa- } \\
\text { tivas nos conceitos e/ou práticas de } \\
\text { comercialização. }\end{array}$ & 2,58 & 2,59 & 2,40 & 2,56 \\
\hline $\begin{array}{l}\text { 9. Implementação de novos métodos e } \\
\text { gerenciamento, visando a atender normas de } \\
\text { certificação (ISO 9000, ISO 14000, etc). }\end{array}$ & 1,50 & 1,53 & 1,20 & 1,48 \\
\hline
\end{tabular}

Fonte: Dados da pesquisa.

Nota: Os valores de cada item foram obtidos através da média das respostas. Para avaliar o grau de inovação utilizou-se a seguinte escala: 1 - não houve a atividade inovação; 2 - a taxa da inovação foi baixa; 3 - a taxa da inovação foi média; e 4 - a taxa da inovação foi alta.

Os indicadores 7 (implementação de significativas mudanças na estrutura organizacional) e 8 (implementação de mudanças significativas nos conceitos e/ou práticas de comercialização) apresentaram médias superiores aos quatro indicadores citados anteriormente. Esse resultado também reflete a proposta de Pavitt (1984), quando afirma que o foco das empresas dominadas pelos fornecedores está no aprimoramento contínuo no design e qualidade de produtos, nas mudanças organizacionais, gerenciais, rotinas de marketing, entre outras.

Vale ressaltar que os indicadores 7 e 8 sinalizam também que o menor porte das empresas pode tornar o processo de implementação de alternati- 
vas estratégicas mais ágeis, pois as micro e pequenas empresas da amostra apresentaram médias superiores às médias e grandes indústrias.

A segunda parte do constructo inovação é relacionada às atividades inovadoras das indústrias do vestuário de Londrina e os resultados estão apresentados na Tabela 3. Nenhum dos oito indicadores selecionados apresentou média geral superior a 3,0, mostrando novamente a baixa taxa de inovação das empresas da amostra. Os indicadores 11 (aquisição externa de P\&D - Pesquisa e Desenvolvimento), 13 (aquisição de outras tecnologias), 14 (projeto industrial ou desenho industrial associados a produtos/processos tecnologicamente novos) e 15 (programa de treinamento orientado à introdução de produtos/processos tecnologicamente novos), ficaram com médias menores que 2,0, confirmando essa situação.

Tabela 3: Atividades inovadoras por porte das empresas.

\begin{tabular}{|c|c|c|c|c|}
\hline Descrição & Micro & Pequena & $\begin{array}{l}\text { Média/ } \\
\text { Grande }\end{array}$ & Geral \\
\hline $\begin{array}{l}\text { 10. Atividades de Pesquisa e Desenvolvi- } \\
\text { mento (P\&D) rea-lizadas na própria } \\
\text { empresa. }\end{array}$ & 2,48 & 2,06 & 1,60 & 2,29 \\
\hline 11. Aquisição externa de P\&D. & 1,50 & 1,53 & 1,60 & 1,52 \\
\hline $\begin{array}{l}\text { 12. Aquisição de máquinas e equipamen- } \\
\text { tos que implicaram em significativas } \\
\text { melhorias tecnológicas de produtos/ } \\
\text { processos ou que estão associados aos } \\
\text { novos produtos/processos. }\end{array}$ & 2,23 & 2,65 & 2,80 & 2,39 \\
\hline $\begin{array}{l}\text { 13. Aquisição de outras tecnologias } \\
\text { (softwares, licenças ou acordos de transfe- } \\
\text { rência de tecnologia, tais como patentes, } \\
\text { marcas, segredos industriais). }\end{array}$ & 1,65 & 2,00 & 2,60 & 1,82 \\
\hline $\begin{array}{l}\text { 14. Projeto industrial ou de-senho industri- } \\
\text { al associados a produtos/processos } \\
\text { tecnologi-camente novos ou significativa- } \\
\text { mente melhorados. }\end{array}$ & 1,55 & 2,12 & 2,00 & 1,74 \\
\hline
\end{tabular}


Tabela 3: Atividades inovadoras por porte das empresas.

\begin{tabular}{|l|c|c|c|c|}
\hline \multicolumn{1}{|c|}{ Descrição } & Micro & Pequena & $\begin{array}{c}\text { Média/ } \\
\text { Grande }\end{array}$ & Geral \\
\hline $\begin{array}{l}\text { 15. Programa de treinamento orientado à } \\
\text { introdução de produtos/processos } \\
\text { tecnologicamente novos ou significativa- } \\
\text { mente melhorados. }\end{array}$ & 2,08 & 1,88 & 1,60 & 1,98 \\
\hline $\begin{array}{l}\text { 16. Programas de gestão da qualidade ou } \\
\text { de modernização organizacional }\end{array}$ & 2,03 & 1,88 & 2,20 & 2,00 \\
\hline $\begin{array}{l}\text { 17. Novas formas de comer-cialização e } \\
\text { distribuição para o mercado, envolvendo } \\
\text { produtos novos ou significativamente } \\
\text { melhorados. }\end{array}$ & 2,55 & 2,47 & 1,80 & 2,47 \\
\hline
\end{tabular}

Fonte: Dados da pesquisa.

Nota: Os valores de cada item foram obtidos através da média das respostas. Para avaliar o grau de inovação utilizou-se a seguinte escala: 1 - não houve a atividade inovação, 2 - a taxa da inovação foi baixa, 3 - a taxa da inovação foi média e 4 - a taxa da inovação foi alta.

Verificam-se médias ligeiramente superiores a 2,0 nos indicadores 10 (atividades de Pesquisa e Desenvolvimento), 12 (aquisição de máquinas e equipamentos), 16 (programas de gestão da qualidade ou de modernização organizacional) e 17 (novas formas de comercialização e distribuição), este último confirmando a preocupação das empresas com novas práticas de comercialização e distribuição, conforme resultados da Tabela 3. É possível observar ainda que as médias e grandes empresas apresentaram resultados superiores à média geral e às micro e pequenas nos indicadores 11, 12, 13 e 16.

\subsection{Análise de Correlação}

Primeiramente serão apresentados os resultados relacionados a toda amostra da pesquisa, ou seja, 62 empresas. A Tabela 4 aponta que a relação existente entre a orientação para o mercado e o desempenho geral mostrouse positiva, porém fraca. Resultado semelhante pode ser observado no coeficiente resultante da relação entre a orientação para o mercado e o indicador crescimento do faturamento. $\mathrm{O}$ mesmo aconteceu com o relacionamento entre a inovação e o desempenho geral e a inovação e o crescimento do 
faturamento; os dois coeficientes resultantes dessas associações foram positivos e fracos.

Os resultados agregados apontam também que a inovação está positivamente relacionada com o indicador retorno do investimento, dessa forma, pôde-se inferir que a orientação para o mercado e a inovação conduzem a um desempenho superior e contribuem para o crescimento do faturamento $e$ para o retorno do investimento nas indústrias do vestuário de Londrina.

Tabela 4: Correlação entre orientação para o mercado, inovação e desempenho (todas as empresas da amostra - 62 indústrias).

\begin{tabular}{|l|c|c|c|c|}
\hline & $\begin{array}{c}\text { Desempe- } \\
\text { nho } \\
\text { Geral }\end{array}$ & $\begin{array}{c}\text { Cresci- } \\
\text { mento do } \\
\text { faturamento }\end{array}$ & $\begin{array}{c}\text { Lucro } \\
\text { Líquido }\end{array}$ & $\begin{array}{c}\text { Retorno } \\
\text { do investi- } \\
\text { mento }\end{array}$ \\
\hline Orientação para o Mercado & $0,287 *$ & $0,304 *$ & 0,210 & 0,206 \\
\hline Inovação & $0,293 *$ & $0,273 *$ & 0,142 & $0,325^{*}$ \\
\hline
\end{tabular}

Fonte: Dados da pesquisa.

Nota: * A correlação é significante ao nível de 0,05.

O próximo passo foi realizar uma análise desagregando as empresas, segundo o porte. Nas microempresas pesquisadas apenas a relação entre a inovação e o indicador retorno do investimento foi significativa, gerando um coeficiente positivo, porém fraco $(0,343)$. As demais relações não apresentaram correlações significantes, conforme mostra a Tabela 5. Embora as microempresas tenham informado que apresentam elevada orientação para o mercado, o resultado efetivo dessa orientação em seu desempenho parece não estar surtindo efeito. Kohli e Jaworski (1990) alertam para esse fato ao lembrarem que nesses casos a qualidade da informação de mercado pode ser suspeita ou a qualidade de execução dos programas de marketing designados em resposta a essa informação pode ser pobre. Nessas situações, uma orientação para o mercado pode não produzir as consequências desejadas. 
Tabela 5: Correlação entre orientação para o mercado, inovação e desempenho (microempresas - 40 indústrias).

\begin{tabular}{|l|c|c|c|c|}
\hline & $\begin{array}{c}\text { Desempe- } \\
\text { nho } \\
\text { Geral }\end{array}$ & $\begin{array}{c}\text { Cresci- } \\
\text { mento do } \\
\text { faturamento }\end{array}$ & $\begin{array}{c}\text { Lucro } \\
\text { Líquido }\end{array}$ & $\begin{array}{c}\text { Retorno } \\
\text { do investi- } \\
\text { mento }\end{array}$ \\
\hline Orientação para o Mercado & 0,159 & 0,129 & 0,144 & 0,109 \\
\hline Inovação & 0,306 & 0,293 & 0,127 & $0,343^{*}$ \\
\hline
\end{tabular}

Fonte: Dados da pesquisa.

Nota: * A correlação é significante ao nível de 0,05.

A Tabela 6 mostra os resultados referentes às correlações realizadas nas pequenas empresas. É possível verificar relações positivas e fortes entre a orientação para o mercado e o desempenho geral, e entre a orientação para o mercado e o crescimento do faturamento. Esses resultados vão ao encontro das descobertas obtidas por Jaworski e Kohli (1993), que sugeriram que a orientação para o mercado de uma empresa é um fator relevante para seu desempenho. Já a inovação não apresentou correlações significativas entre os indicadores de desempenho no grupo das pequenas empresas.

Tabela 6: Correlação entre orientação para o mercado, inovação e desempenho (pequenas empresas -17 indústrias).

\begin{tabular}{|l|c|c|c|c|}
\hline & $\begin{array}{c}\text { Desempe- } \\
\text { nho } \\
\text { Geral }\end{array}$ & $\begin{array}{c}\text { Cresci- } \\
\text { mento do } \\
\text { faturamento }\end{array}$ & $\begin{array}{c}\text { Lucro } \\
\text { Líquido }\end{array}$ & $\begin{array}{c}\text { Retorno } \\
\text { do investi- } \\
\text { mento }\end{array}$ \\
\hline Orientação para o Mercado & $0,594^{*}$ & $0,624^{*}$ & 0,461 & 0,448 \\
\hline Inovação & 0,159 & 0,092 & $-0,024$ & 0,354 \\
\hline
\end{tabular}

Fonte: Dados da pesquisa.

Nota: * A correlação é significante ao nível de 0,05. 
Nenhuma das correlações realizadas nas médias e grandes empresas foi significativa, conforme a Tabela 7. Embora os coeficientes tenham sido elevados na maioria dos testes, os poucos casos envolvidos na análise (cinco empresas) dificultaram a verificação das relações.

Tabela 7: Correlação entre orientação para o mercado, inovação e desempenho (médias e grandes empresas - 5 indústrias).

\begin{tabular}{|l|c|c|c|c|}
\hline & $\begin{array}{c}\text { Desempe- } \\
\text { nho } \\
\text { Geral }\end{array}$ & $\begin{array}{c}\text { Cresci- } \\
\text { mento do } \\
\text { faturamento }\end{array}$ & $\begin{array}{c}\text { Lucro } \\
\text { Líquido }\end{array}$ & $\begin{array}{c}\text { Retorno } \\
\text { do investi- } \\
\text { mento }\end{array}$ \\
\hline Orientação para o Mercado & 0,823 & 0,759 & 0,729 & 0,732 \\
\hline Inovação & 0,497 & 0,618 & 0,469 & 0,247 \\
\hline
\end{tabular}

Fonte: Dados da pesquisa.

Com o objetivo de identificar grupos de empresas com características semelhantes em relação à inovação, orientação para o mercado e desempenho, os dados colhidos referentes a esses constructos foram submetidos à Análise de Cluster. A diversidade de conduta é um dos aspectos destacados pela literatura schumpeteriana.

Dos três clusters encontrados, o agrupamento 2 foi o que apresentou os melhores resultados em praticamente todas as dimensões analisadas. Esse grupo é formado por 18 empresas (29\% do total da amostra); ele apresenta uma alta orientação para o mercado, buscando gerar e disseminar informações de mercado para responder-lhe de forma efetiva por meio de um comportamento inovador, pois nesse grupo a dimensão inovação também obteve a maior média em relação aos outros dois clusters. Tais características permitem que o agrupamento possa ser compreendido na presente pesquisa como o que apresenta um comportamento estratégico altamente voltado para o mercado e inovador, sendo designado como cluster competitivo.

O cluster 1 apresentou médias de orientação para o mercado inferiores ao do grupo competitivo, porém foram significativas. As médias encontradas apontam também que o agrupamento apresenta comportamento pouco inovador. Os resultados sinalizam que as práticas adotadas pelo cluster 1 tendem a gerar um desempenho superior, pois a média desse constructo foi ligeiramente superior aos grupos 2 e 3 . Esse grupo, diante do resultado de sua 
formação, pode ser considerado como o que possui um comportamento estratégico orientado para o mercado e com baixa atividade inovadora, sendo designado como cluster padrão.

O cluster 3, formado por 18 empresas, foi o que apresentou as médias mais baixas em todas as dimensões analisadas, sendo esse grupo constituído por empresas com média (tendendo a baixa) orientação para o mercado. Ele está se voltando mais para a resposta ao mercado do que para os processos de disseminação e geração de inteligência de mercado. Sua atividade inovadora é praticamente nula. O resultado do agrupamento acaba por refletir no desempenho das empresas, pois a média também foi a mais baixa dentre os três clusters. Em relação à formação desse grupo, as empresas que o constituem podem ser consideradas como as que apresentam um comportamento estratégico que busca responder ao mercado e não inovador, sendo designado como cluster reativo. A Tabela 8 apresenta os resultados e é possível verificar que os testes de significância apontam diferenças significativas entre as médias encontradas.

Tabela 8: Composição dos clusters.

\begin{tabular}{|l|c|c|c|c|}
\hline & $\begin{array}{c}\text { Cluster } \\
\text { Padrão }\end{array}$ & $\begin{array}{c}\text { Cluster } \\
\text { Competitivo }\end{array}$ & $\begin{array}{c}\text { Cluster } \\
\text { Reativo }\end{array}$ & Significância \\
\hline Geração de inteligência & 3,75 & 4,47 & 3,09 & 0,000 \\
\hline Disseminação de inteligência & 4,08 & 4,69 & 3,07 & 0,000 \\
\hline Resposta à inteligência & 4,20 & 4,65 & 3,86 & 0,000 \\
\hline Orientação para o mercado & 4,03 & 4,60 & 3,43 & 0,000 \\
\hline Inovação & 2,10 & 2,34 & 1,71 & 0,000 \\
\hline Desempenho & 2,78 & 2,74 & 2,31 & 0,004 \\
\hline
\end{tabular}

Fonte: Dados da pesquisa.

A seguir são discutidas características de cada cluster em relação ao ano de fundação das empresas, porte, tipo de gestão e utilização de marca própria. Essa análise tem como objetivo aprimorar as informações dos agrupamentos.

Ao analisar a associação do ano de fundação das empresas com os clusters, na Tabela 9, constata-se que no cluster padrão existe maior predominância de empresas mais antigas, iniciadas entre 1980 e 1989, ao contrário do que ocorreu no cluster competitivo, em que é possível verificar certa 
predominância de empresas fundadas a partir de 1990 até o ano passado. O cluster reativo apresentou uma distribuição similar ao cluster competitivo, pois aproximadamente $53 \%$ das empresas do grupo foram fundadas entre 1980 e 1999 e as demais (47\%), de 2000 até 2005.

Tabela 9: Cruzamento dos clusters de acordo com o ano de fundação das empresas (valores em \%).

\begin{tabular}{|l|c|c|c|}
\hline & De 1980 a 1989 & De 1990 a 1999 & De 2000 a 2005 \\
\hline Cluster Padrão & 33,3 & 58,3 & 8,3 \\
\hline Cluster Competitivo & 16,7 & 33,3 & 50,0 \\
\hline Cluster Reativo & 29,4 & 23,5 & 47,1 \\
\hline
\end{tabular}

Fonte: Dados da pesquisa.

Através dos resultados da Tabela 10 é possível identificar que o cluster competitivo é formado exclusivamente por micro e pequenas empresas. $\mathrm{O}$ segundo grupo com maior quantidade de micro e pequenas empresas é o cluster padrão, juntas elas correspondem a $88,5 \%$ do total do grupo. Já o cluster reativo é o que apresenta a menor quantidade de microempresas, indicando certa tendência de apresentar em sua formação empresas maiores.

Tabela 10: Cruzamento dos clusters de acordo com o porte das empresas (valores em \%).

\begin{tabular}{|l|c|c|c|}
\hline & Micro & Pequena & Média/Grande \\
\hline Cluster Padrão & 65,4 & 23,1 & 11,5 \\
\hline Cluster Competitivo & 72,2 & 27,8 & 0,0 \\
\hline Cluster Reativo & 55,6 & 33,3 & 11,1 \\
\hline
\end{tabular}

Fonte: Dados da pesquisa.

No que diz respeito à caracterização dos clusters em relação ao tipo de gestão, praticamente não houve associações significativas no cruzamento realizado. Percebe-se apenas certa predominância de empresas familiares no cluster padrão; nos dois outros agrupamentos a distribuição entre empresas familiares e mistas foi homogênea, conforme a Tabela 11. 
Tabela 11: Cruzamento dos clusters de acordo com o tipo de gestão (valores em \%).

\begin{tabular}{|l|c|c|}
\hline & Familiar & Mista \\
\hline Cluster Padrão & 57,7 & 42,3 \\
\hline Cluster Competitivo & 50 & 50 \\
\hline Cluster Reativo & 50 & 50 \\
\hline
\end{tabular}

Fonte: Dados da pesquisa.

Na Tabela 12 é possível observar a predominância de empresas que trabalham com suas próprias marcas nos três agrupamentos. Porém o cluster padrão se destaca como aquele que apresenta o maior percentual de empresas com esse comportamento. O cluster reativo também apresenta uma quantidade significativa de empresas que operam com marcas próprias e, por último, o cluster competitivo apresenta em sua formação o menor percentual de empresas com essa estratégia.

Tabela 12: Cruzamento dos clusters de acordo com a utilização de marca própria (valores em \%).

\begin{tabular}{|l|c|c|}
\hline & Sim & Não \\
\hline Cluster Padrão & 96,2 & 3,8 \\
\hline Cluster Competitivo & 77,8 & 22,2 \\
\hline Cluster Reativo & 88,9 & 11,11 \\
\hline
\end{tabular}

Fonte: Dados da pesquisa.

\section{Conclusão}

Foi possível constatar através da pesquisa a baixa implementação de atividades inovadoras por parte das empresas pesquisadas. Os resultados confirmam a taxonomia proposta por Pavitt (1984), em que caracteriza as indústrias do vestuário como dominadas pelos fornecedores, sendo as inovações desenvolvidas fora das empresas. De maneira geral, identificou-se que a maior preocupação das indústrias do vestuário de Londrina está no lançamento de produtos que são novos para elas, mas já existentes no mercado. Dois outros indicadores mostram que o porte das empresas também pode auxiliar nos processos inovadores. De acordo com a pesquisa, as mu- 
danças na estrutura organizacional e mudanças nas práticas de comercialização foram os itens em que as micro e pequenas empresas superaram as médias e grandes. Reafirma-se também com esses dois indicadores a proposta de Pavitt (1984) quando cita que o foco das empresas dominadas por fornecedores está no aprimoramento dos produtos, mudanças organizacionais e rotinas de marketing. Foi constatado também que as empresas do arranjo local estão orientadas para o mercado, dirigindo suas ações no sentido de gerar informações de mercado, disseminá-las internamente e responder ao mercado de acordo com suas exigências.

A análise de correlação realizada permitiu identificar que, de forma geral, a inovação e a orientação para o mercado conduzem a um desempenho superior, e estão contribuindo para o crescimento do faturamento e para o retorno do investimento nas indústrias pesquisadas, confirmando os pressupostos teóricos e empíricos discutidos na revisão da literatura.

Ainda em relação aos resultados positivos encontrados nas relações entre orientação para o mercado e inovação no desempenho das empresas, a pesquisa sinaliza a necessidade da implementação do conceito de marketing $e$ da adoção de práticas inovadoras por parte das indústrias do vestuário. Neste sentido, o poder público local, os órgãos de apoio, as entidades de classe, as universidades, enfim, todos os agentes do arranjo podem contribuir com know-how para articular as ações estratégicas de mudança.

Dentre essas ações, a presente pesquisa destaca como fundamentais em relação às praticas inovadoras: i) promoção da conscientização da relevância da inovação para a competitividade das empresas através da criação de projetos de informação sobre capacitação tecnológica; ii) capacitação de recursos humanos para a prática inovadora através da oferta de cursos técnicos; iii) expansão de ações cooperativas visando o desenvolvimento de processos inovadores.

A análise de cluster realizada na pesquisa aponta que os grupos pertencentes a um mesmo arranjo produtivo local apresentam dinâmicas diferenciadas, com características diferentes sinalizando a necessidade de políticas de incentivos diferenciados. O grupo competitivo pode ser utilizado como modelo de atuação para as empresas dos outros grupos e para todo o arranjo, podendo inclusive assumir a liderança na coordenação de ações visando o desenvolvimento de todo o aglomerado, representando o setor perante os outros agentes. 
Ao grupo padrão caberiam ações pontuais nos fatores que podem transformá-lo em um grupo mais competitivo, principalmente em ações voltadas para a geração de informação de mercado, sendo essa dimensão o ponto de partida para as ações de marketing e análise de tendências de mercado. Nesse sentido, as ações estariam ligadas ao financiamento para realização de pesquisas de marketing, subsídios para participação em eventos nacionais e internacionais, capacitação dos empresários para a realização de planos de marketing. Já o grupo reativo necessitaria de ações de intervenção mais críticas, de longo prazo, talvez com incentivos financeiros diferenciados, linhas de crédito atrativas, de forma a modernizar a estrutura produtiva, capacitação de pessoal e atualização da linha de produtos. As intervenções nesse grupo também não poderiam deixar de lado questões ligadas ao aprimoramento das práticas e disseminação dos conceitos de marketing como fundamentais para o desenvolvimento das empresas.

\title{
Innovation, market orientation and performance in the local embryonic productive arrangement of clothing in Londrina/PR
}

\begin{abstract}
This research analyzes the impact on both the innovation and market orientation related to the companies' performance of the local productive arrangement of clothing in Londrina. It identifies the rank of market orientation through the Markor scale, elaborated by Kohli, Jaworski and Kumar (1993) and the product innovation implementation, process and organizational innovations. The chosen method is the survey, involving a sample of 62 companies, and to proceed with the data analysis we use the coefficient of correlation of Pearson and the Clusters Analysis. The main results are: a) the companies are highly market oriented; b) the innovative behavior of the arrangement is low; c) the launching of new products has been the most innovative practice used by the companies; d) the market orientation and innovation contribute to the income growth and to the return of investment of the clothing industries in Londrina.
\end{abstract}

Key-words: Market orientation. Innovation. Competitiveness. Clothing industry. 
Fabiano Palhares Galão - Marcia Regina Gabardo Da Camara

\section{REFERÊNCIAS}

ARBEX, Marco A. Aglomeração industrial de empresas do vestuário no município de Londrina. 2005. Dissertação (Mestrado em Administração) Programa de Pós-Graduação em Administração - PPA, UEL/UEM. Londrina, 2005.

BRAGA, Clarice A. Acirramento da concorrência e alterações nas estratégias competitivas na indústria de vestuário: o caso do APL de Petrópolis. Rio de Janeiro. 2005. Dissertação (Mestrado em Economia) - IE/ UFRJ. Rio de Janeiro, 2005.

CAMPOS, Rentao R.; CÁRIO, Sílvio A. F.; NICOLAU, José A. Arranjos e sistemas produtivos locais $e$ as novas políticas de desenvolvimento industrial e tecnológico. Nota Técnica 20. Rio de Janeiro: Instituto de Economia da Universidade Federal do Rio de Janeiro - IE/UFRJ, 2000.

CARNEIRO, Jorge M. T. et al. Mensuração do Desempenho Organizacional: questões conceituais e metodológicas. In: ENCONTRO DE ESTUDOS EM ESTRATÉGIA, 2., 2005, Rio de Janeiro. Anais... Rio de Janeiro: 3Es, 2005. 1 CD-ROM.

CASSIOLATO, José E.; LASTRES, Helena M. M. O foco em arranjos produtivos e inovativos locais de micro e pequenas empresas. In: LASTRES, Helena M. M.; CASSIOLATO, José E. (Coord.). Arranjos produtivos locais: uma nova estratégia de ação para o Sebrae. Rio de Janeiro: RedeSist, 2004.

DOSI, Giovani. The nature of the innovative process. In: DOSI, G. et al. (Eds). Technical Change and Economic Theory. London: Pinter Publishers, 1988.

FINEP - FINANCIADORA DE ESTUDOS E PROJETOS. Relatório Setorial Preliminar: setor têxtil e vestuário. FINEP: jan. 2004.

GARCIA, Renato; MOTTA, Flávia Gutierrez; AMATO NETO, João. Uma análise das características da estrutura de governança em sistemas locais de produção e suas relações com a cadeia global. Gestão \& Produção, São Carlos, v. 11, n. 3, p. 343-354, set./dez. 2004.

HAIR Jr., Joseph F. et al. Fundamentos de métodos de pesquisa em administração. Porto Alegre: Bookman, 2005.

HOOLEY, Graham J.; SAUNDERS, John A.; PIERCY, Nigel F. Estratégia de marketing e posicionamento competitivo. São Paulo: Prentice Hall, 2001. 
HURLEY, Robert F.; HULT, G. Tomas M. Innovation, market orientation, and organizational learning: An integration and empirical examination. Journal of Marketing, Chicago, IL, v. 62, p. 42-54, jul. 1998.

IEMI - INSTITUTO DE ESTUDOS E MARKETING INDUSTRIAL. Relatório Setorial da Cadeia Têxtil Brasileira. São Paulo, v. 5, n. 5, ago. 2005.

JAWORSKI, Bernard J.; KOHLI, Ajay K. Market Orientation: antecedents and consequences. Journal of Marketing, Chicago, IL, v. 57, p. 53-71, jul. 1993.

KOHLI, Ajay K.; JAWORSKI, Bernard J. Market orientation: the construct, research propositions, and managerial implications. Journal of Marketing, Chicago, IL,v. 54, p. 1-18, abr. 1990.

KOHLI, Ajay K.; JAWORSKI, Bernard J.; KUMAR, Ajith. MARKOR: a measure of market orientation. Journal of Marketing Research, Chicago, IL, v. 30, p. 467-477, nov. 1993.

LASTRES, Helena M. M. et al. Globalização e inovação localizada. In: CASSIOLATO, Jorge E.; LASTRES, Helena M. M. (Orgs.). Globalização e inovação localizada: experiências de sistemas locais no Mercosul. Brasília: IBICT/IEL, 1998.

LASTRES, Helena M. M.; CASSIOLATO, Jorge E. Novas políticas na era do conhecimento: o foco em arranjos produtivos e inovativos locais. Parcerias estratégicas, Brasília, n. 17, set. 2003.

LASTRES, Helena M. M. (Coord.). Glossário de Arranjos e Sistemas Produtivos e Inovativos. In: Arranjos produtivos locais: uma nova estratégia de ação para o Sebrae. Rio de Janeiro: RedeSist, set. 2004.

LEMOS, Cristina. Inovação em arranjos e sistemas de MPME - NT 1.3. Rio de Janeiro: IE/UFRJ, 2001.

LEVIN, Jack. Estatística aplicada a ciências humanas. São Paulo: Harbra, 1987.

MARSHALL, Alfred. Princípios de economia. São Paulo: Abril Cultural, 1982.

MARTINS, Flavio E. V. Estratégias competitivas e inovação na indústria do vestuário: um estudo exploratório em empresas do RS. Dissertação (Mestrado em Administração) - PGA/Escola de Administração, UFRGS. Porto Alegre, 2003. 
Liana Souza da Rosa - Marcos Baptista Lopes Dalmau - Alessandra de Linhares Jacobsen

MENNA, Hélio L. Orientação para o mercado e performance: Evidências em empresas Gaúchas de varejo de confecções masculinas. In: ENCONTRO ANUAL DA ANPAD, 25., 2001, Curitiba. Anais... Campinas: ANPAD, 2001. 1 CD-ROM.

MINGOTI, Sueli A. Análise de dados através de métodos de estatística multivariada: uma abordagem aplicada. Belo Horizonte: UFMG, 2005.

PAVITT, Keith. Sectoral Patterns of Technical Change: towards a taxonomy and a theory. Research Policy, North-Holland, n. 13, p. 343-373, 1984.

PERIN, Marcelo G.; SAMPAIO, Cláudio H. O papel da inovação na relação entre a orientação para o mercado e a performance empresarial. ENCONTRO DE MARKETING, 2, 2006, Rio de Janeiro. Anais... Rio de Janeiro: EMA, 2006. 1 CD-ROM.

RICHARDSON, Roberto Jarry. Pesquisa social. 2. ed. São Paulo: Atlas, 1989.

SANTOS, Fabiana; CROCCO, Marco; LEMOS, Mauro B. As micro, pequenas e médias empresas em espaços industriais periféricos: estudo comparativo entre arranjos produtivos locais de subsistência e centro-radial. In: LASTRES, Helena M. M.; CASSIOLATO, José Eduardo; MACIEL, Maria Lucia (Org.). Pequena empresa: cooperação e desenvolvimento local. Rio de Janeiro: Relume Dumará, 2003.

SANTOS, Fabiana; CROCCO, Marco; SIMÕES, R. Arranjos produtivos locais informais: uma análise de componentes principais para Nova Serrana e Ubá Minas Gerais. Ensaios FEE, Porto Alegre, v. 24, n. 1, p. 177-202, 2003.

SOUSA, Tamara R. V.; CAVALCANTI FILHO, Paulo F. Arranjos produtivos locais: uma análise dos APLs coreiro-calçadistas gaúcho e paraibanos. In: ENCONTRO DA SOCIEDADE BRASILEIRA DE ECONOMIA POLÍTICA, 9, 2004, Uberlândia. Anais... Uberlândia: set. 2004.

SUZIGAN, Wilson et al. Sistemas Locais de Produção: Mapeamento, Tipologia e Sugestões de Políticas In: ENCONTRO NACIONAL DE ECONOMIA, 31, 2003. Porto Seguro. Anais... Porto Seguro: ANPEC, 2003.

TELLES, Luciana Oliveira. Cluster e a indústria ligada à saúde em Ribeirão Preto. Ribeirão Preto. 2002. (Dissertação de Mestrado) - Faculdade de Economia, Administração e Contabilidade da Universidade de São Paulo. Ribeirão Preto, 2002. 